\title{
Effects of Iron, Nickel, and Cobalt on Precipitation Hardening of Alloy 718
}

\author{
J.R. Groh ${ }^{*}$ and J.F. Radavich ${ }^{* *}$ \\ * GE Aircraft Engines \\ Evendale Ohio \\ $* *$ School of Materials Engineering \\ Purdue University
}

\begin{abstract}
An investigation was performed to evaluate the effects of nickel and cobalt substitutions for all or part of the iron on the precipitation hardening behavior of Alloy 718. Isothermal exposures of solution heat treated wrought material were conducted to provide material for hardness testing and metallographic evaluation. A time-temperature-hardness diagram was prepared for each iron, nickel, and cobalt combination. Scanning electron microscopy was performed to document microstructural features while phase identification was performed using $X$-ray diffraction and energy dispersive spectroscopy of extracted residues.

The types of precipitates observed, potential age hardenability, and delta solvus temperatures were independent of iron, nickel, and cobalt content. However, the presence of iron in the 718 alloy system was shown to cause incipient melting and to significantly increase the rate of precipitation and the tendency to over-age. The onset of over-aging in the iron-bearing alloys was attributed to $\tau^{\prime \prime}$ coarsening and was accelerated by the growth of delta platelets at the expense of $\tau$ ". The time-temperature-hardness diagrams of the iron-free alloys did not display closed isohardness curves characteristic of isothermal over-aging.
\end{abstract}




\section{Introduction}

Early Alloy 718 development efforts by Eiselstein ${ }^{(1)}$ et al focused primarily on high tensile strengths and secondarily on the microstructural stability necessary for extended service at elevated temperatures. The nickel and iron concentration of the commercially available alloys were established for a system containing (weight \%) 15. chromium, 6. niobium, 3. molybdenum, .6 aluminum, .6 titanium, and .005 boron. The combination of nickel and iron was selected as $53 \%$ and $19 \%$, respectively, to optimize room temperature strengths and the 100 -hour rupture stress at $1200^{\circ} \mathrm{F}$. The same investigator reported that the optimum 100 -hour rupture stress at $1300^{\circ} \mathrm{F}$ and $1400^{\circ} \mathrm{F}$ occurred when iron was completely replaced by nickel. Further published information regarding an iron-free version of 718 has not been reported.

Muzyka's ${ }^{(2)}$ comparison of precipitation-strengthened nicke1-îron base superalloys relative to nickel base superalloys showed the following general trends as iron content is increased:

1. Lowered solubility temperatures of precipitating phases.

2. Increased susceptibility to formation of eta and delta.

3. Increased susceptibility to formation of deleterious phases such as Laves, $\sigma$, and $\mathrm{Mu}$.

4. Replacement of $\tau^{\prime}$ by $r^{\prime \prime}$ as niobium content is increased.

5. Altered precipitate-matrix relationships since iron has a larger atomic diameter than nickel.

These trends may be due to differences in whole alloy compositions and not solely to the presence of iron. A systematic investigation of iron reductions in a nickel-iron base system has not been reported.

It was anticipated that the effect of replacing iron with nickel would be complicated by its participation in nearly all phases present in Alloy 718. If excess hardening elements (niobium, aluminum, and titanium) are available, nickel additions would permit further precipitation. Conversely, excess nickel in the $\tau$ matrix may increase solid solubility for hardeners and reduce the volume fraction of precipitates. Substitution of cobalt for iron was performed to clarify the effects of iron on age behavior as cobalt has not been reported to participate strongly in the Ni-side of anticipated phases, cobalt should partition to the $\tau$-matrix similar to iron alloying.

Incremental removal of iron in this investigation was accomplished by substituting either nickel or cobalt or a combination of both. The balance of the nominal composition was maintained constant to enable comparison of the influence of iron, nickel, and cobalt alloying on the precipitation hardening behavior of this alloy system. Hardness data were used in this investigation as an economical indicator of mechanical strength. Microstructural effects were correlated to hardness as a function of thermal exposure for each iron, nickel, and cobalt combination. 


\section{Materials}

A total of six compositions were prepared by Special Metals Corporation (SMC) as $15 \mathrm{lb}$ VIM heats. Iron was removed from the baseline $20 \mathrm{w} / \mathrm{o}$ in nominal increments of $10 \mathrm{w} / \mathrm{o}$ using systematic substitutions of nickel and cobalt. The balance of the alloy was maintained at the baseline composition with a nominal niobium content $5.3 \mathrm{w} / \mathrm{o}$. Each alloy was cast and hot rolled Lo minimize segregation effects using a thermal-mechanical processing schedule typical for Alloy 718. Roll-down stock measured approximately 0.5 in. thick and 2.375 in. wide by 12 in. in length.

\section{$\underline{\text { Procedure }}$}

Chemical analysis of each alloy was performed utilizing vacuum emission spcctrography and inductively-coupled plasma emission spectroscopy for the appropriate elements listed in table $\mathrm{I}$.

Because the alloys were hot rolled using an Alloy 718-type schedule, it was necessary to solution heat treat each relative to a critical metallurgical temperature to minimize the effects of non-optimized thermal-mechanical processing. As-received specimens were prepared to provide a reference hardness and microstructure for the solution heat treat study. A roughly $0.5 \mathrm{in}$. cube of each alloy was subjected to a temperature in the 1800-2025 F range for one hour and water quenched. The delta solvus temperature was evidenced by recrystallization and interrupted grain growth due to solutioning of this grain boundary pinning phase. The solution temperature of each alloy was selected to produce a nominal grain diameter of $30 \mu \mathrm{m}$ in anticipation of follow-on mechanical property evaluations and to minimize variables relative to bulk versus grain boundary diffusion rates.

An isothermal age study was conducted to determine the precipitation hardening behavior of each alloy after solutioning at the pre-determined solution temperatures. Isothermal aging was performed on 0.5 in. cubes of each alloy at $1200,1300,1400$, and $1500^{\circ} \mathrm{F}$ using exposure times of $0.1,1 ., 4 ., 8 ., 24 ., 48 .$, and 96 hours. Additional specimens were aged at 1600 $\mathrm{F}$ for 1 and 4 hours and $1100^{\circ} \mathrm{F}$ for 4 hours.

The average of six hardness tests performed on a short-transverse face of each specimen was plotted on a temperature versus log time scale. Isohardness curves were drawn through the data to represent Rockwel1 C 20, $25,30,35,38,40$, and 42 as appropriate.

Derived time-temperature-hardness diagrams were used to select conditions of interest for optical and scanning electron metallography. Phase identification was performed using both comparison of microstructures to published 1 iterature and $X$-ray diffraction of extracted residues. Metallographic specimens were prepared via electropolish at 25 volts in $20 \%$ $\mathrm{H}_{2} \mathrm{SO}_{4}$ and clectroetch at 5 volts in $10 \mathrm{cc} \mathrm{H} \mathrm{SO}_{4}, 172 \mathrm{cc} \mathrm{H} \mathrm{PO}_{4}$, and $16 \mathrm{~g} \mathrm{CrO}_{3}$. Résidues for diffraction analysis were extracted using $10 \%$ HCl at 5 volts. 


\section{$\underline{\text { Results }}$}

Differential thermal analysis by Special Metals Corporation indicated that substitution of either $\mathrm{Ni}$ or Co for half or more of the $\mathrm{Fe}$ in the baseline alloy eliminated incipient melting and increased the solidus temperature by $30-80 \mathrm{~F}$. Chemistry (in wt\%) and DTA results are provided in table I. Results of the solution study of each alloy after a 1-hour exposure are given in table II.

\begin{tabular}{|c|c|c|c|c|c|c|c|}
\hline Lab ID & $\underline{A}$ & $\underline{B}$ & $\underline{\underline{C}}$ & $\underline{D}$ & $\underline{E}$ & $\underline{\underline{F}}$ & AMS 5663 \\
\hline $\mathrm{Ni}$ & $5 \overline{1} .6$ & $6 \overline{1} .6$ & $6 \overline{9} .8$ & $5 \overline{2} .9$ & $5 \overline{4} .2$ & $6 \overline{2} .8$ & $50 .-55$. \\
\hline $\mathrm{Fe}$ & 20.2 & 9.8 & $<.05$ & 10.1 & 0.25 & $<.05$ & remainder \\
\hline Co & $<.05$ & $<.05$ & $<.05$ & 8.6 & 17.6 & 8.8 & $1.0 \max$ \\
\hline Mo & 3.20 & 3.20 & 3.02 & 3.10 & 3.19 & 3.0 & $2.8-3.3$ \\
\hline $\mathrm{Nb}+\mathrm{Ta}$ & 5.28 & 5.13 & 5.14 & 5.05 & 5.31 & 5.09 & $4.75-5.5$ \\
\hline $\mathrm{Ti}$ & 0.94 & 0.96 & 0.93 & 0.90 & 0.92 & 0.86 & $0.65-1.15$ \\
\hline Al & 0.46 & 0.58 & 0.53 & 0.48 & 0.48 & 0.47 & $0.2-0.8$ \\
\hline $\mathrm{Mn}$ & 0.04 & 0.04 & 0.04 & 0.04 & 0.03 & 0.04 & $0.35 \mathrm{max}$ \\
\hline Si & 0.06 & 0.06 & 0.05 & 0.06 & 0.04 & 0.05 & $0.35 \mathrm{max}$ \\
\hline C & 0.03 & 0.02 & 0.03 & 0.03 & 0.04 & 0.03 & $0.08 \max$ \\
\hline B & .003 & .001 & .003 & .003 & .003 & .002 & $0.006 \max$ \\
\hline$S$ & .007 & .006 & .008 & .006 & .006 & .006 & $0.015 \max$ \\
\hline$P$ & .004 & .002 & .004 & .005 & .005 & .004 & $0.015 \max$ \\
\hline $\mathrm{Cu}$ & $<.01$ & $<.01$ & $<.01$ & 0.01 & 0.01 & 0.01 & $0.30 \max$ \\
\hline & 2219 & 2278 & not & 2248 & 2282 & 2300 & $\ldots-\ldots$ \\
\hline & 2119 & & orted & & & & \\
\hline
\end{tabular}

Table II Average Grain Diameter $(\mu \mathrm{m})$ and Hardness

Lab As- One-hour Exposure Temperature

ID Rcvd 1800F 1825F $1850 \mathrm{~F}$ 1875F $1900 \mathrm{~F}$ 1950F $1975 \mathrm{~F}$ 2000F 2025F

\begin{tabular}{|c|c|c|c|c|c|c|c|c|c|c|}
\hline A & $20 \phi$ & $\overline{\ldots-}$ & $\ldots$. & 20 & $32 x$ & 36 & 38 & $\ldots$ & $\ldots$ & $\ldots$ \\
\hline B & $18 \phi$ & $\ldots--$ & $\ldots$ & 22 & 25 & $35 *$ & 50 & $\ldots$ & $\ldots$ & $-\ldots$ \\
\hline C & $19 \phi$ & $\ldots$ & $\ldots$ & $\ldots$ & 26 & $31 *$ & 44 & $\ldots$ & $\cdots$ & \\
\hline D & $14 \phi$ & 15 & 24 & 25 & $\cdots$ & $28 *$ & 36 & $\ldots$ & $\ldots$ & \\
\hline $\mathrm{E}$ & $15 \phi$ & - . - & $\ldots$ & 15 & 20 & $28 *$ & 29 & $\ldots$ & $\ldots-$ & $\cdots$ \\
\hline $\mathbf{F}$ & $14 \phi$ & $\ldots$ & $\ldots$ & 15 & $\ldots$ & 16 & 21 & $\ldots$ & $31 *$ & 45 \\
\hline & ir & & 001 & Ced & Lut & temp & rat & & & \\
\hline A & $28 \mathrm{Rc}$ & $\ldots$ & $\ldots$ & $91 \mathrm{Rb}$ & $86 \mathrm{Rb}$ & $85 \mathrm{Rb}$ & $85 \mathrm{Rb}$ & - - & & \\
\hline B & $25 \mathrm{Rc}$ & $\ldots$ & $-\cdots$ & $94 \mathrm{Rb}$ & $90 \mathrm{Rb}$ & $87 \mathrm{Rb}$ & $87 R b$ & $\ldots$ & $\ldots$ & \\
\hline $\mathrm{C}$ & $32 \mathrm{Rc}$ & ---- & $-\cdots$ & $\cdots$ & $94 \mathrm{Rb}$ & $91 \mathrm{Rb}$ & $90 \mathrm{Rb}$ & $\cdots$ & $\cdots$ & \\
\hline D & $32 \mathrm{Rc}$ & $94 \mathrm{Rb}$ & $90 \mathrm{Rb}$ & $93 \mathrm{Rb}$ & $-\ldots$ & $90 \mathrm{Rb}$ & $90 \mathrm{Rb}$ & $\cdots$ & $\ldots$ & \\
\hline $\mathrm{E}$ & $37 \mathrm{Rc}$ & $\ldots$ & $\ldots$ & $99 \mathrm{Rb}$ & $93 \mathrm{Rb}$ & $92 \mathrm{Rb}$ & $94 \mathrm{Rb}$ & $\ldots$ & $\ldots$ & $\cdots$ \\
\hline $\mathrm{F}$ & $35 \mathrm{Rc}$ & $-\ldots$ & $--\cdot-$ & $94 \mathrm{Rb}$ & $\ldots$ & $92 \mathrm{Rb}$ & $92 \mathrm{Rb}$ & $91 \mathrm{Rb}$ & $88 \mathrm{Rb}$ & $86 \mathrm{Rk}$ \\
\hline
\end{tabular}

The actual delta solvus of each alloy occurred within the $1825-1875^{\circ} \mathrm{F}$ range. The solution temperature selecled for each alloy is indicated with an asterisk.

Isohardness curves derived from the isothermal age exposures are shown in the time-temperature-hardness (TTH) diagrams shown in figures 1 through 6 for comparison of the precipitation hardening behavior of these alloys. 


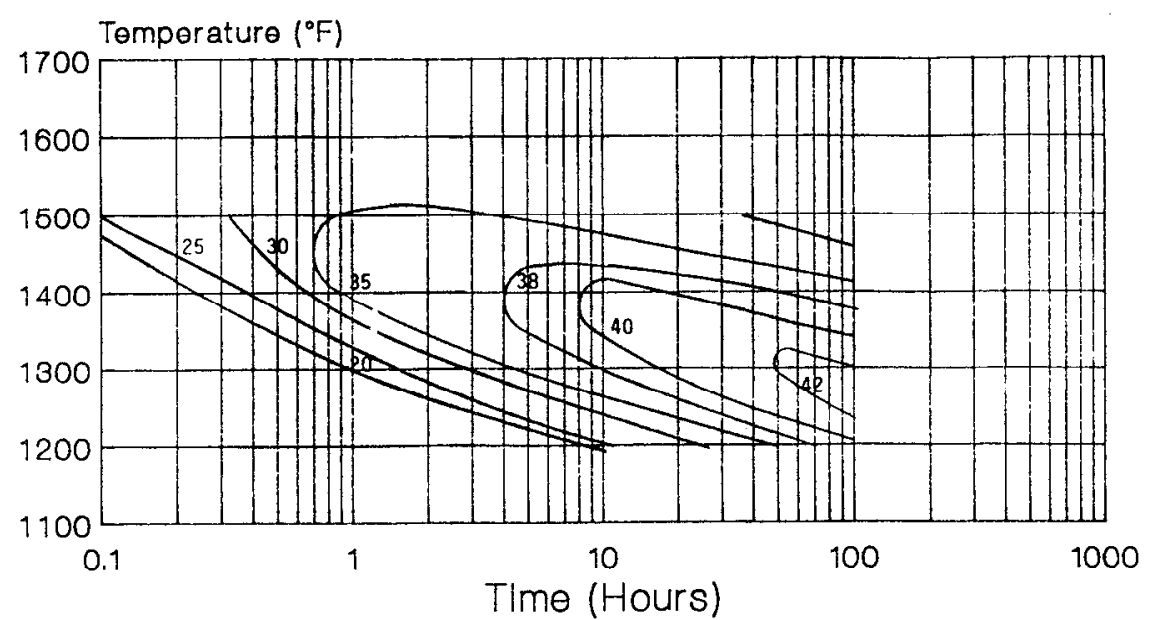

Figure 1 - TTH diagram for baseline alloy A (20Fe-52Ni-0Co)

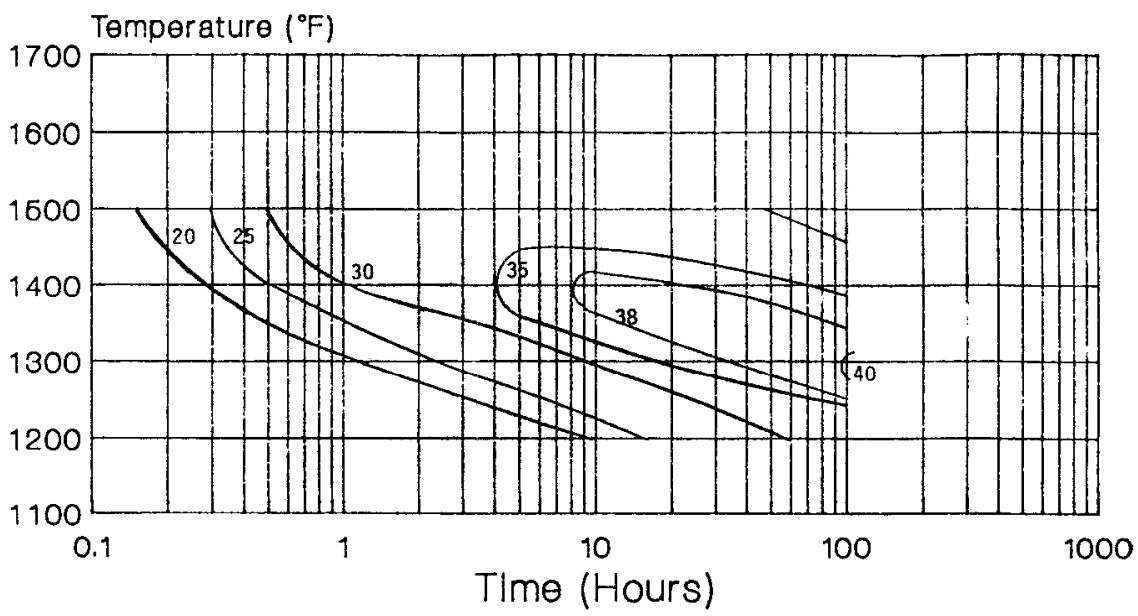

Figure 2 - TTH diagram for alloy B (10Fe-62Ni-0Co)

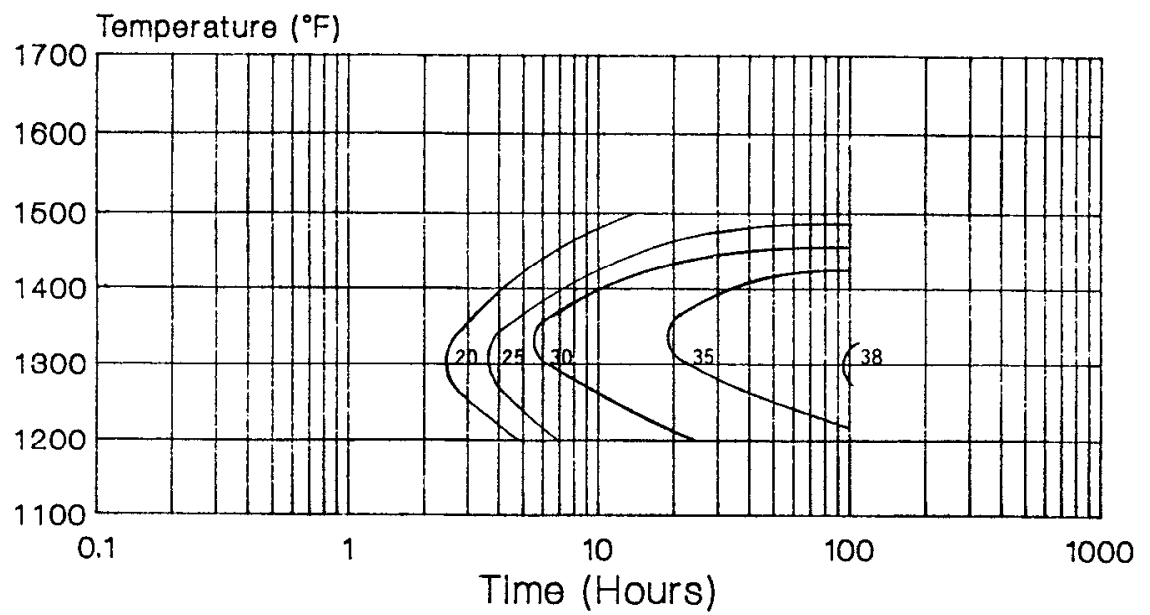

Figure 3 - TTH diagram for Alloy C (OFe-70Ni-OCo) 


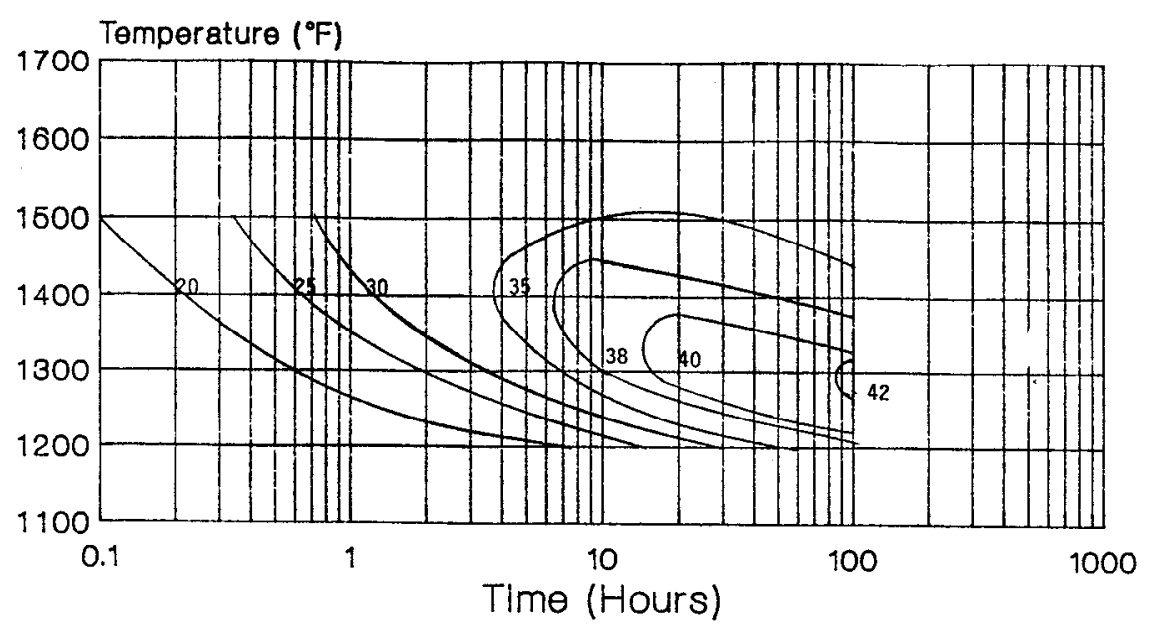

Figure 4 - TTH diagram for Alloy D (10Fe-53Ni-9Co)

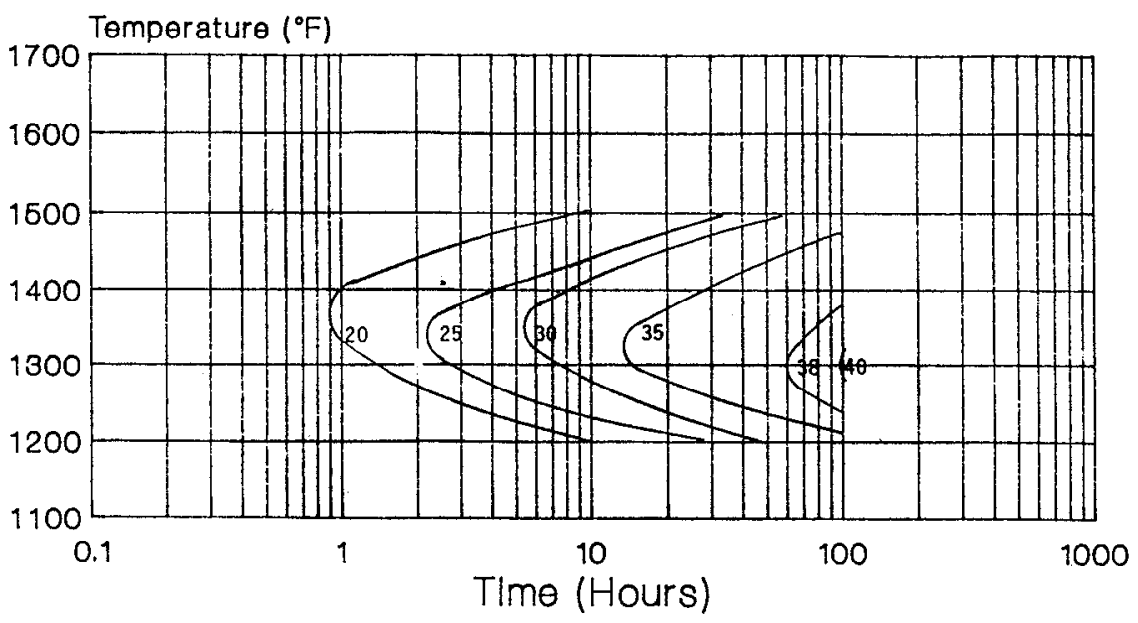

Figure 5 - TrH for Alloy E (0Fe-54Ni-18Co)

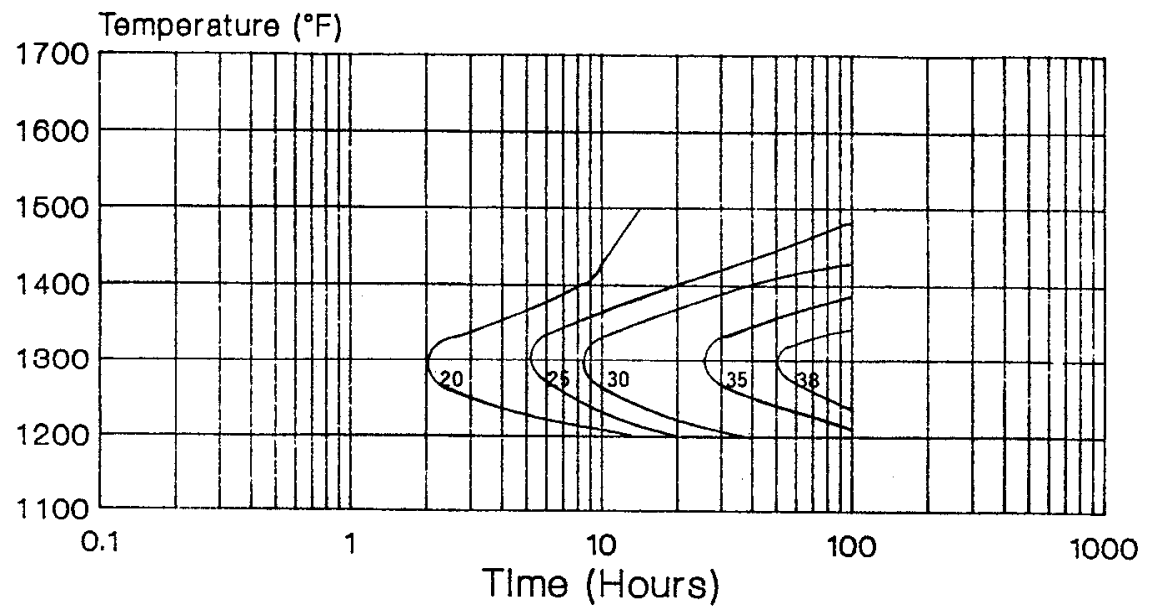

Figure 6 - TTH for Alloy F (0Fe-63Ni-9Co) 
Electron microscopy of selected isothermal age conditions revealed that each alloy precipitates $r^{\prime \prime}, r^{\prime}$, and delta phases typified by figure 7 .

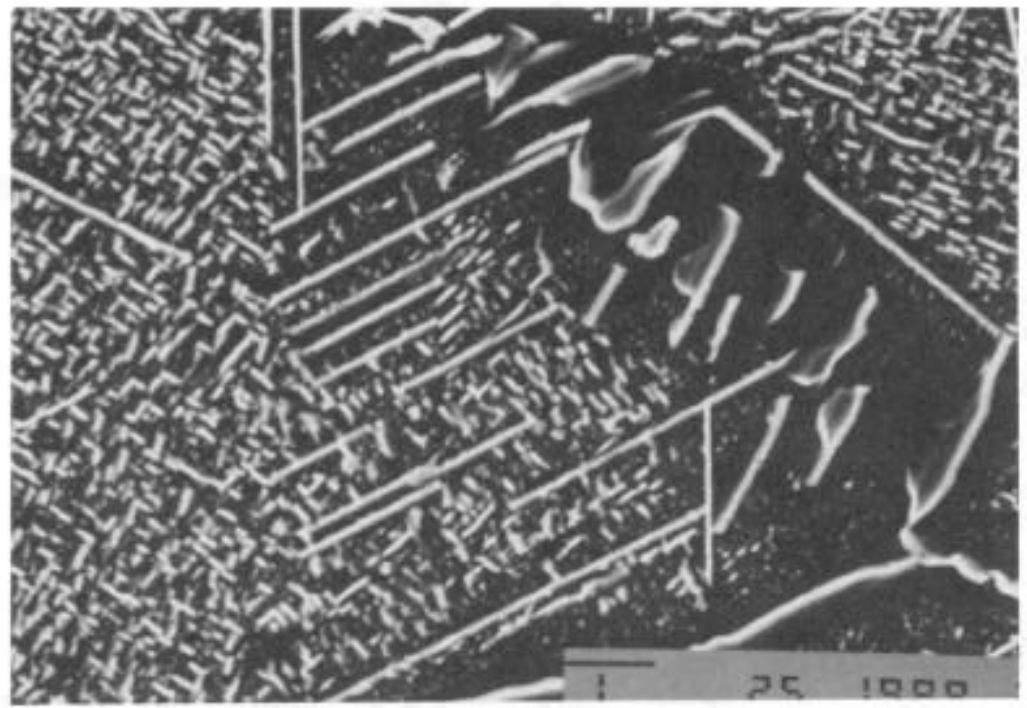

Figure 7 - Alloy D (10Fe-53Ni-9Co) after $1500 \mathrm{~F}$ for 8 hours, 31Rc.

Effective resolution of the SEM was insufficient to observe initiation of $\tau^{\prime \prime} / \tau^{\prime}$ precipitation; therefor, the point at which $\mathrm{Rc} 20$ is attained was used as a measure of the onset of precipitation for this study. Higher temperatures and/or time caused $r "$ coarsening with a coincident change from a spheroidal to a disc morphology having a maximum dimension of $0.8 \mu \mathrm{m}$. The $r^{\prime}$ remained spheroidal reaching a maximum size of $0.1 \mu \mathrm{m}$. Precipitation of delta phase was observed to initiate as discrete particles at grain and twin boundaries. Further exposure caused delta coarsening in a platelike morphology along grain boundaries and, eventually, into the grain. The nominal platelet size ranged from 0.15 to $20 . \mu \mathrm{m}$. The maximum temperatures at which $r^{\prime \prime}, r^{\prime}$, and delta precipitates were observed are illustrated in figure 8. Where appropriate, the time to solution at the maximum temperature at which the phase was observed is indicated.

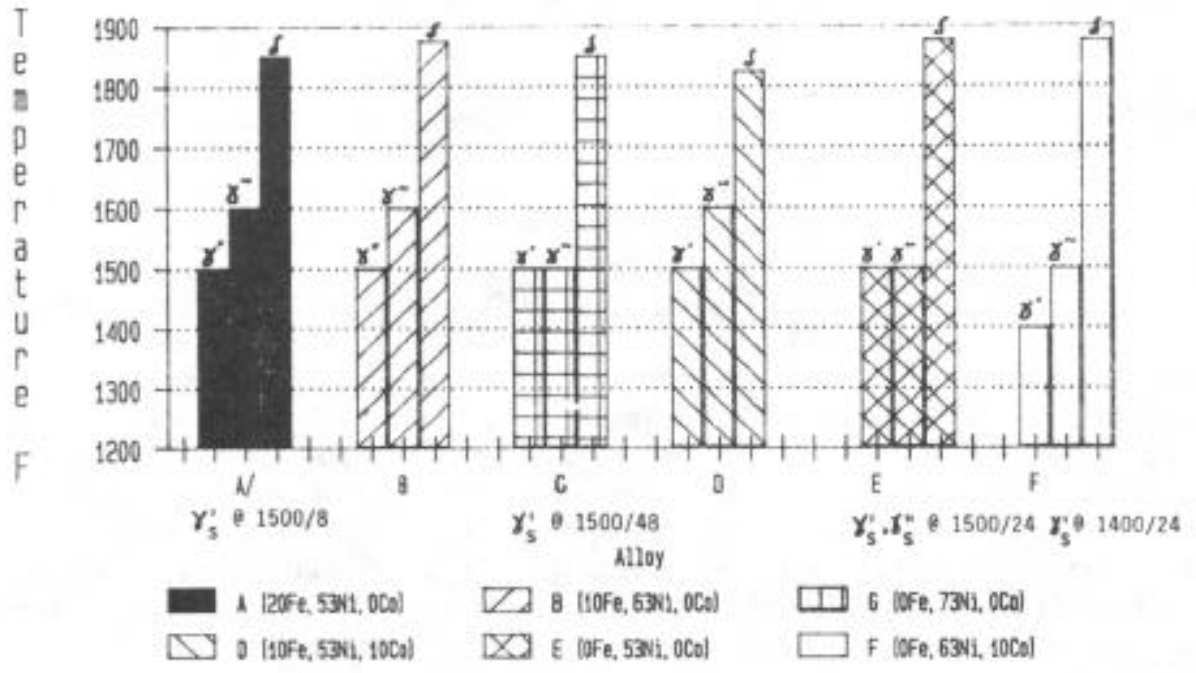

Figure 8 - Maximum precipitate temperatures of each alloy. 


\section{Discussion}

The data generated for alloy A confirmed that the base line material accurately represents commercial wrought Alloy 718 . The temperatures at which over-aging occurred compare favorably to that reported elsewhere. 'The delta start curve published by Boesch and Canada intersects the TTH curves slightly before reaching maximum hardness. The AMS5663 thermal treatment achieved the Rc 42 hardness maximum observed by isothermal aging without a sub-critical anneal.

The solution study revealed no significant influence of $\mathrm{Fe}$, $\mathrm{Ni}$, and Co level on the delta solvus temperature. Differences in the solution temperature necessary to reach a $30 \mu \mathrm{m}$ grain diameter were considered to be related more to material cleanliness than difrusion rates as the "fish-mouth" area of the roll-downs was utilized for the solution study. The similarity in hardness of the six alloys after solution heat treat indicated that $C o$ and $\mathrm{Fe}$ are not effective solid solution hardening elements in this alloy system as reported elsewhere for $\mathrm{Co}$ in $\mathrm{Ni}$.

The types of precipitates observed were independent of $\mathrm{Fe}, \mathrm{Ni}$, and Co leve1. Comparison of TTH diagrams for alloy A (20Fe-52Ni-0Co) versus the reduced $\mathrm{Fe}$ alloys shows that the base line composition reached HRc 20 in the least amount of time throughout the temperature range evaluated. The same alloy system over-aged at temperatures as low as $1300^{\circ} \mathrm{F}$ as evidenced by the closed isohardness loops.

Alloys B (10Fe-62Ni-0Co) and D (10Fe-53Ni-9Co) also display closed loops although these occur at longer times than alloy $A$. The Ni substitution resulted in a slightly longer time to a given hardness than the Co substitution. The maximum hardness attained for alloy $B$ was Rc 40 versus Rc 43 for alloy $D$.

Iron-free alloys C (0Fe-70Ni-0Go), E (0Fe-54Ni-18Co), and F (0Fe-63Ni-9Co) did not exhibit closed isohardness loops in the range of exposures evaluated. Again, the $\mathrm{Ni}$ substitution generally reached a given hardness at a longer exposure than the alloy with a Co substitution. The maximum hardness attained for alloys C, E, and F were Rc38, Rc40, and Rc39, respectively.

Assuming that additional exposure would have further hardened alloys $\mathrm{C}$, $E$, and $F$ to the nominal Rc 42 maximum observed for the Fe-bearing alloys, the potential age hardenability appears to be independent of $\mathrm{Fe}, \mathrm{Ni}$, and Co concentrations. The Rc 20, 30, and 38 curves of each alloy are replotted in figure 9 for comparison of hardening rates. Complete removal of Fe significantly decreases hardening rates, with a $N i$ substitution being slightly slower than a Co substitution (alloys B vs. D; G vs. E; G vs. F).

As hardness loss in the Fe-bearing alloys occurred at and below temperatures at which delta phase precipitated, it was concluded that over-aging occurred primarily to $\tau^{\prime \prime}$ coarsening. The formation and growth of delta platelets appears to further accelerate the over-age reaction. Delta was observed to coarsen at the expense of $r^{\prime \prime}$ as illustrated in figure 10 which contrasts with the proponents of $\tau^{\prime \prime}$ solutioning to provide $\mathrm{Nb}$ necessary for delta growth. It appears that depletion of $\mathrm{Nb}$ by delta precipitation changes local composition to the extent that $\tau^{\prime}$ forms. This also occurred in the $\mathrm{Nb}$-depleted areas surrounding primary carbides at conditions beyond the bulk $\tau^{\prime}$ solvus as shown in figure 10 . 


\section{Time-Temperature-Hardness}
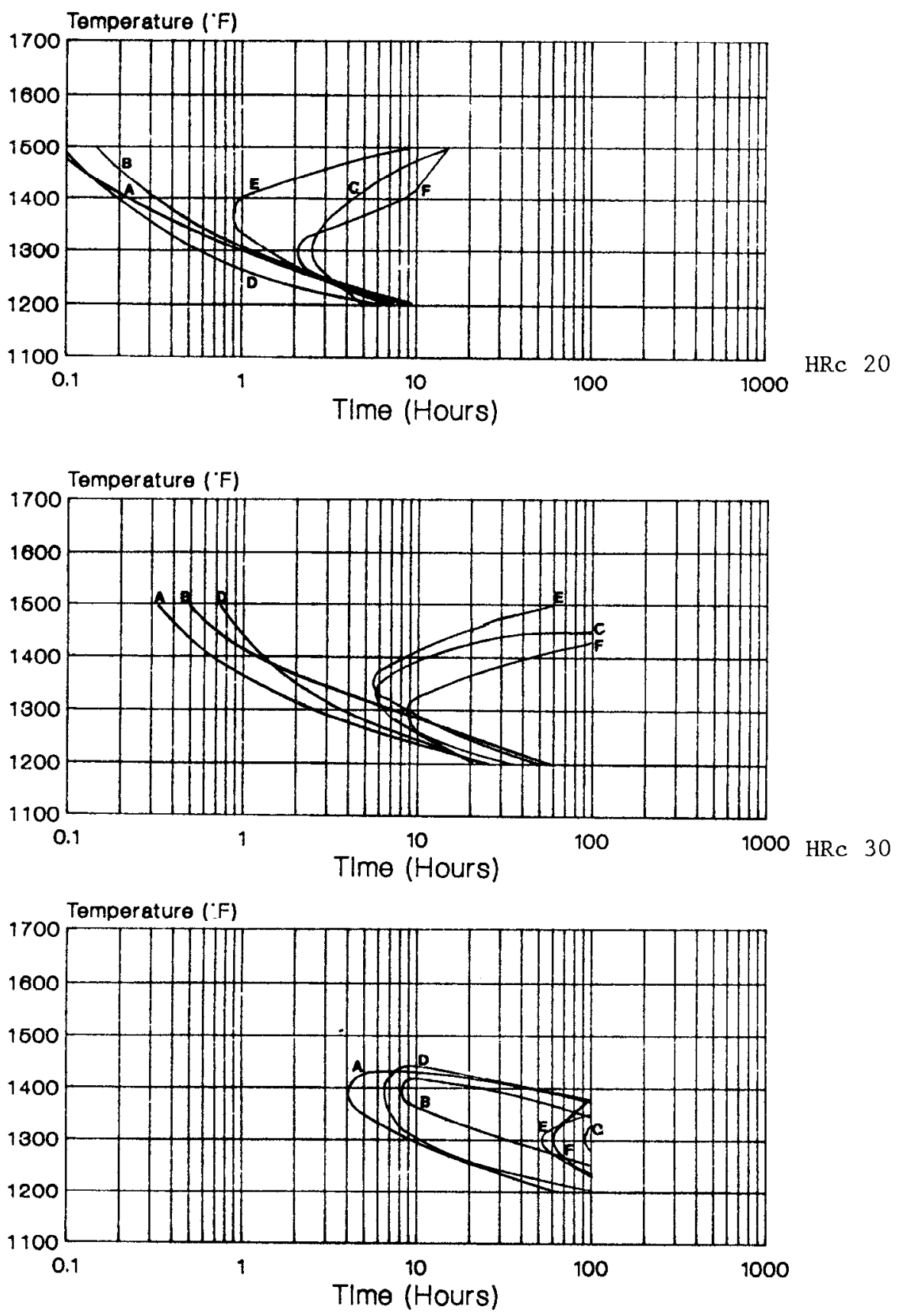

HRC 38

Figure 9 - Isohardness curves of each alloy plotted for comparison

While equipment limitations prevented observation of the onset of $\tau$ " $/ \tau^{\prime}$ precipitation, it seems logical that as $\tau$ " precipitates in these alloys, it creates an adjacent zone lean in $\mathrm{Nb}$ until local composition favors $\tau^{\prime}$ precipitation. This interdependent mechanism is in agreement with reference 7 and in marked concrasl wilh leference 9 which advocates that $r "$ precipitates on pre-existing $r^{\prime}$ particles. 


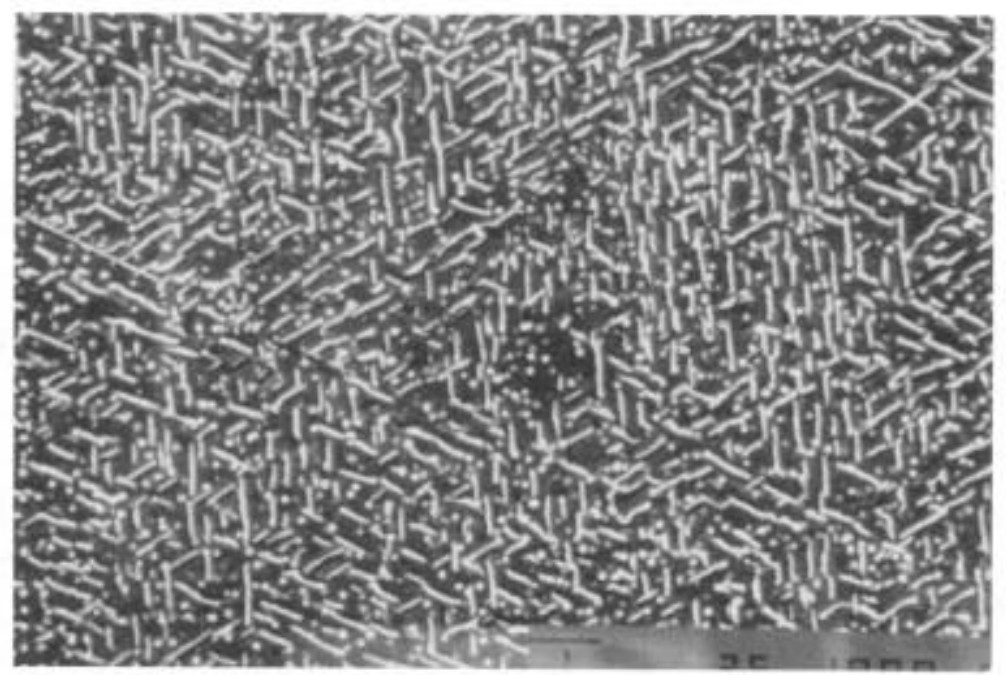

Alloy B (10Fe-62Ni-0Co) $1500^{\circ} \mathrm{F} / 96 \mathrm{Hrs}, 28 \mathrm{HRc} 7500 \mathrm{X}$

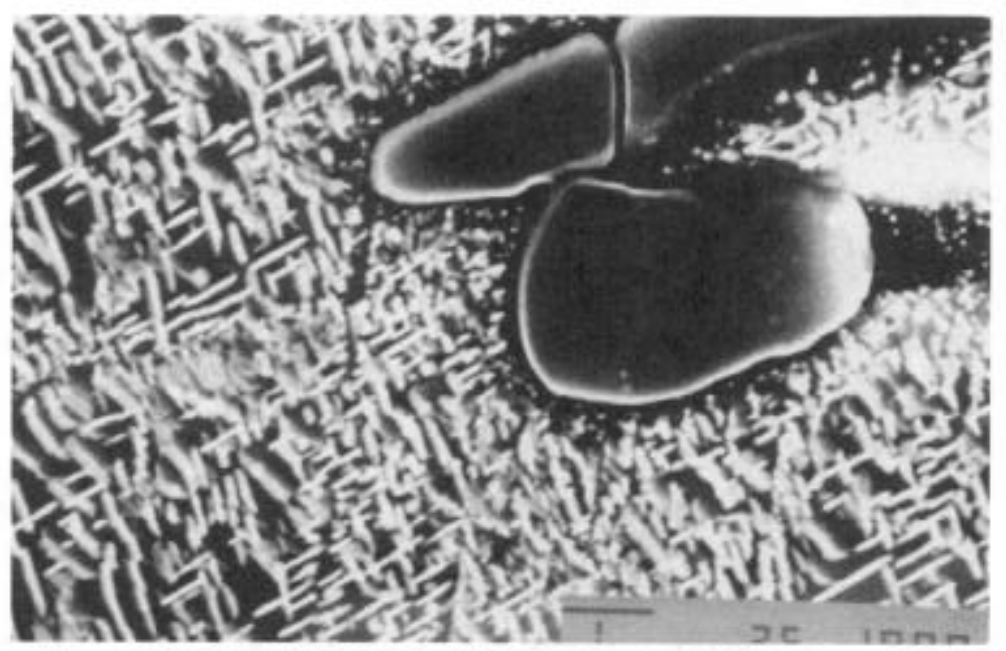

Alloy $\mathrm{F}(\mathrm{OFe}-63 \mathrm{NI}-9 \mathrm{Co}) 1400^{\circ} \mathrm{F} / 96 \mathrm{Hrs}, 34 \mathrm{HRc} 10000 \mathrm{X}$

Figure 10 - Micrographs illustrating $\tau^{\prime}$ formed in $\mathrm{Nb}$-lean areas $\mathrm{A}$ ) between $\tau "$ precipitates and B) adjacent to primary carbides

Alloying with $\mathrm{Fe}$ appears to accelerate aging kinetics by increasing diffusivity of elements necessary for precipitate formation and growth. Substitution of $\mathrm{Fe}$ for either $\mathrm{Ni}$ or Co has been reported to expand the lattice of the $\mathrm{Ni}-\mathrm{Fe}$ matrix ${ }^{(8)}$, the larger lattice may enhance diffusion of hardening $\xi_{0}$ lements (ie, $\mathrm{Ni} / \mathrm{Nb} / \mathrm{Ti} / \mathrm{Al}$ ). Comparison of the interatomic distance of $\mathrm{Fe}(\tau-2.5786 \mathrm{~A}), \mathrm{Co}(2.5010 \mathrm{~A})$, and $\mathrm{Ni}(2.4916 \mathrm{~A})$ shows the same trend as the rate of precipitation hardening. As diffusivity has been reported to vary with the square of interatomic distance, it would be expected that substitution of either Ni or Co for Fe would inhibit precipitation whereas substitution of $\mathrm{Ni}$ for Co would have a relatively slight effect. As reported in reference 11 for the Fe-Co-Ni ternary system, $\mathrm{D}(\mathrm{Fe})>\mathrm{D}(\mathrm{Co}) \approx \mathrm{D}(\mathrm{Ni})$.

\section{Conclusions}

- Substitution of either Ni or Co for half or more of the Fe in Alloy 718 eliminated the incipient melting and increased the solidus temperature by $60-80^{\circ} \mathrm{F}$.

- The types of phases precipitated $\left(\tau^{\prime \prime}, \tau^{\prime}\right.$, delta and NbC) were independent of $\mathrm{Fe}, \mathrm{Ni}$, and Co concentration. 
- The $\tau^{\prime \prime}$ solvus temperature was reduced approximately $100^{\circ} \mathrm{F}$ when either $\mathrm{Ni}$, Co, or a combination of both was substituted for the $\mathrm{Fe}$ in Alloy 718. Additionally, substitution of half $\mathrm{Ni}$ and half Co for the Fe reduced the $\tau^{\prime}$ solvus by $100^{\circ} \mathrm{F}$. The delta solvus temperature was not significantly affected by $\mathrm{Fe}, \mathrm{Ni}$, and Co level.

- Reduction of $\mathrm{Fe}$ content significantly increased the thermal exposure time necessary to reach a given hardness while the potential age hardenability appeared to be unaffected.

- The Fe-containing alloys displayed closed isohardness curves indicative of isothermal over-aging. The Fe-free alloys showed no evidence of isothermal over-aging within the time-temperature range evaluated.

- Over-aging of the Fe-bearing alloys was attributed primarily to $\tau$ " coarsening and secondarily to the formation and growth of delta phase at the expense of $\tau^{\prime \prime}$.

\section{Acknowledgements}

The authors wish to thank Special Metals Corporation for providing material and to the Allison Gas Turbine Division of General Motors for providing funding and facilities to perform the majority of this project. In addition, the supportive interest of Dr. S. Bashir of GM is gratefully acknowledged.

\section{References}

1. Eiselstein, "Metallurgy of a Columbium-Hardened Nicke1- Chromium-Iron Alloy.", ASTM STP 369, 1965, 62-79.

2. Muzyka, "The Metallurgy of Nicke1-Iron Alloys", Sims \& Hagel, eds., The Superalloys, Wiley \& Sons, 1972, 113-143.

3. Paulonis, Oblak, and Duval1, "Precipitation in Nickel-base Alloy 718", Transactions of the ASM, Vo1.62, 1969, 611-612.

4. Radavich, "Metallography of Alloy 718.", Journal of Metals, July $1988,42-48$.

5. Barker, Ross, and Radavich, "Long Time Stability of Incone1 718.", Journal of Metals, January 1970 .

6. Boesch and Canada, "Precipitation Reactions and Stability of $\mathrm{Ni}_{3} \mathrm{Cb}$ in Inconel Alloy 718.", Int. Symposium on Structural Stability in Superalloys, Vol. II, Sept. 4-6, 1968, 579-596.

7. Brooks and Bridges, "Long Term Stability of Inconel Alloy 718 for Turbine Disc Applications.", Proc. of Conf. held in Liege, Belgium, 6-9 oct. 1986, High Temperature Alloys for Gas Turbines and other Applications 1986, Part II, Reidel Publishing Co., 1986, 1431-1440.

8. Dyson and Holmes, "Effect of Alloying Additions on the Lattice Parameter of Austenite.", Journal of the Iron and Steel Institute, May $1970,469-474$.

9. Cozar and Pineau, "Morphology of $\tau^{\prime}$ and $\tau$ " Precipitates and Thermal. Stability of Inconel 718 Type Alloys.", Metallurgical Transactions, Volume 4, January $1973,47-59$.

10. W.B. Pearson, A Handbook of Lattice Spacings and Structures of Metals and Alloys, Pergammon Press, 1958.

11. Vignes and Sabatier, "Ternary Diffusion in Fe-Co-Ni Alloys.", Transactions of the Metallurgical Society of ATMF, Vo1.245, Aug.1969, 1795-1802. 